\title{
COMMENTARY
}

\section{Can the US Health Care Industry Be Improved Without Blowing It Up?}

David S. Guzick, MD, PhD

(Fam Med. 2020;52(3):168-70.)

doi: 10.22454/FamMed.2020.246837

C an the United States improve the balance of care, cost, and access in its health care industry without blowing it up? I answer in the affirmative. For the 90\% of the population who have health care coverage, there are many ways to improve care quality while reducing cost. Moreover, it should be possible to enhance access for the $10 \%$ who are uninsured. On the other hand, there is substantial risk in radically restructuring health care under Medicare for All.

More spending on health care should result in commensurate improvements in health status and access. Yet the reverse is paradoxically true in the United States: compared with other high-income countries, the United States spends almost twice as much per person, but has the lowest life expectancy, highest infant mortality, and worst access. ${ }^{1}$ The claims-based, utilization-driven, private health insurance backbone of US health care is no doubt responsible for a large part of this imbalance. The question before us as a nation, however, is whether the United States is better off imposing a single-payer system of universal coverage that eliminates private health insurance, or instead rebalancing care, cost, and access for the $90 \%$ of the population with coverage, and enhancing access for those who are currently uninsured.

Senate Bill S 1129, the Medicare for All Act of $2019,{ }^{2}$ is the current benchmark for a federal single-payer system of universal coverage. It has many strengths: the problem of access is essentially solved, administrative costs of claims processing are reduced, pharmacy prices are reduced and rebates/coupons are eliminated, and cost-effectiveness analysis and evidence-based practice could potentially be more readily promulgated. There are major risks, however:

- The entire health care sector-\$3.5 trillion, or almost one-fifth of US GDPwould come under the executive branch of the federal government. When, in the future, there is a recession that deepens an already record federal budget deficit, and/or an administration that believes in reducing deficits and debt through cost reduction, available resources for health care throughout the nation could be bluntly slashed with minimal checks and balances. Besides the budget, decisions about a variety of issues affecting health care coverage and delivery could be made by executive rule, an unsettling thought in view of unchecked federal agency decisions made in recent years.

- As written, the required resources are not sustainable. Quite apart from the cost and workforce needs of providing coverage for 30 million uninsured Americans and better coverage for 30-40 million underinsured, there are other major implications. One pertains to health insurance premiums for state employees and the state share of Medicaid expenses; these are now covered by state budgets but would become a federal taxpayer expense. Another is the elimination of copays and deductibles, which would add

From the University of Florida, Gainesville, FL. 
hundreds of billions of dollars to federal expenditures based on a well-known randomized trial that found that individuals with a zero copay spent about $20 \%$ more than those with a $25 \%$ copay. ${ }^{3}$ The marked increase in utilization would also lead to major workforce shortages, especially affecting primary care physicians who would be facing dramatic increases in demand for their services. A third is that savings from planned lower payments to hospitals and doctors would not flow back to the federal government to offset costs. Recent estimates of federal spending under a single-payer system like Medicare for All indicate that additional net federal revenues of $\$ 32$ trillion would be needed over the next decade. ${ }^{4}$

- The macroeconomic consequences of eliminating private health insurance would be profoundly disruptive, with no precedent in US history in size or scope. ${ }^{5}$ Substantial impact on employment, financial markets, and the national money supply and its turnover would be unavoidable.

Does it make sense that, given our current level of health care expenditure relative to peer nations, we should spend even more? Would it not make more sense to implement strategies that can improve health status and access while reducing cost? The following list of initiatives, if implemented, could move the United States substantially in that direction. All would be staunchly opposed by the affected stakeholder(s).

1. Create, disseminate, and utilize information on comparative effectiveness and cost effectiveness, upon which coverage decisions would be made. Based on recommendations of an independent national panel, as exists in many other countries, the goal would be to provide coverage for things that work (ie, cost-effective treatments and practice innovations) while reducing or eliminating coverage for things that don't work. As applied to primary care, such evidence could guide rational policies pertaining to effective treatments, but also regarding telemedicine, wearable technology, digital communication, and the appropriate distribution of services among physicians and other providers according to acuity and complexity.

2. Reduce expenditures on prescription drugs. A major step would be to introduce
Medicare price negotiation (eg, as in House Resolution $3^{6}$ ) regarding launch prices and price increases. It would also be beneficial to create price transparency in the pharmaceutical supply chain, curtail copay coupons, restrict patent evergreening, and create more stringent rules on direct-to-consumer advertising.

3. Reduce billing and insurance-related (BIR) administrative costs. BIR expenses for insurers and providers together account for $20 \%-25 \%$ of insurance premiums. ${ }^{7}$ These could be materially reduced by establishing a national health care identifier, a national claims database, and standardized rules for electronic claims processing (as does, for example, the US credit card system) for all insurers, providers and electronic health record vendors.

4. Reestablish, for all insurers, minimum thresholds for the percent of premiums used to pay medical expenses (ie, medical loss ratio). The ACA established thresholds of $80 \%$ for small-group and $85 \%$ for largegroup plans. These thresholds establish reasonable operating profits for insurers but have been breached under new rules for small-group and individual plans.

5. Expand self-insurance and direct contracting. Employers that self-insure retain the administrative expenses of a third-party administrator, which are often lower than those embedded in commercial premiums. The profit margin that would have gone to the insurer is retained, reducing overall health care expenditures. Direct contracting of self-insured firms with specific health systems or networks can further reduce BIR costs.

6. Reduce provider-induced demand through value-based insurance design (VBID). This is being done with VBIDs directed at patients, which reduce or eliminate copays for high-value services and increase copays for low-value services. Thus far, there has been more attention to the former and less to the latter. There are also VBIDs directed at physicians through the development of narrow networks that focus on physicians who deliver high-value care.

7. Enhance access. Among 27.5 million uninsured in 2016, 3.9 million were ineligible due to immigration status. Of the remaining 23.6 million, 6.8 million were already eligible for Medicaid coverage in expansion states and 7.8 million were eligible for subsidies under ACA exchanges. ${ }^{8}$ 
Thus, efforts to enroll those eligible under current laws could potentially reduce the uninsured rate by up to one-half. Of the remaining 8.8 million uninsured, a variety of policies and programs could enroll a substantial share. Recent modeling of alternative national health care proposals that build upon the existing health insurance platform indicates that universal or near-universal coverage could be achieved with $\$ 20$ billion less in total health care expenditures annually, but require a (relatively) modest $\$ 150$ billion of additional net federal spending. ${ }^{4}$

An analysis of waste in US health care that broadly includes the categories discussed above yielded estimates ranging from $\$ 760$ billion to $\$ 935$ billion, with the potential to reduce $25 \%$ of this waste from recognized interventions. ${ }^{9}$ The above reforms, and others, could both reduce waste and improve care and outcomes. Implementation of reforms, plus policies to enhance access of the uninsured, seem preferable to a single-payer plan that would create unsustainable expenditures and potentially tumultuous change to one-fifth of the economy.

CORRESPONDENCE: Address correspondence to Dr David S. Guzick, University of Florida Clinical and Translational Science Building, 2004 Mowry Rd, Rm 3417, Gainesville, FL 32610. 352-273-5418. Fax: 352-273-8703. dguzick@ufl.edu.

\section{References}

1. Papanicolas I, Woskie LR, Jha AK. Health care spending in the United States and other high-income countries. JAMA. 2018;319(10):1024-1039.
2. Medicare for All Act of 2019, S 1129, 116th Cong, 1st Sess (2019). https://www.congress.gov/bill/116th-congress/senatebill/1129/text. Accessed October 18, 2019.

3. Manning WG, Newhouse JP, Duan N, Keeler EB, Leibowitz A, Marquis MS. Health insurance and the demand for medical care: evidence from a randomized experiment. Am Econ Rev. 1987;77(3):251-277.

4. Blumberg L, Holahan J, Buettgen M, Gangopadhyaya A, Garrett B, Shartzer A, Simpson M, Wang R, Favreault MM, Arnos D. From Incremental to Comprehensive Health Care Insurance Reform: How Various Reform Options Compare on Coverage and Costs. Washington, DC: The Commonwealth Fund; October 16, 2019. https://www.urban.org/sites/default/ files/2019/10/15/from_incremental_to_comprehensive_health_ insurance_reform-how_various_reform_options_compare_on coverage_and_costs.pdf. Accessed October 18, 2019.

5. Abelson R, Sanger-Katz M. Medicare for All Would Abolish Private Insurance: "There's No Precedent in American History." The New York Times. March 23, 2019. https://www. nytimes.com/2019/03/23/health/private-health-insurancemedicare-for-all-bernie-sanders.html. Accessed March 24, 2019.

6. Elijah E. Cummings Lower Drug Costs Now Act, HR3, 116th Congress (2019). https://www.congress.gov/bill/116thcongress/house-bill/3. Accessed October 18, 2019.

7. Kahn JG. Excess billing and insurance-related administrative costs. In: Young PL, Saunders RS, Olsen L, eds. The Healthcare Imperative: Lowering Costs and Improving Outcomes. Washington, DC: National Academies Press; 2010:142-151.

8. Garfield R, Damico A, Orgera K, Claxton G, Levitt L. Estimates of Eligibility for ACA Coverage among the Uninsured in 2016. Washington, DC: Kaiser Family Foundation; June 19, 2016. http://files.kff.org/attachment/Data-Note-Estimatesof-Eligibility-for-ACA-Coverage-among-the-Uninsuredin-2016. Accessed October 18, 2019.

9. Shrank WH, Rogstad TL, Parekh N. Waste in the US Health Care System: estimated costs and potential for savings. JAMA. 2019;322(15):2019; Epub ahead of print. 